\begin{tabular}{c} 
MarkETING AND BRANDING \\
RESEARCH \\
INDUSTRIAL \\
MANAGEMENT \\
INSTITUTE \\
\hline
\end{tabular}

\title{
Usage of health-themed public service announcements as a social marketing communication tool: A content analysis related to public service announcements in the republic of Turkey, ministry of health's web site
}

\author{
Burcu İnci $^{1 *}$, Oya Sancar ${ }^{2}$, Seda H. Bostanci ${ }^{3}$ \\ ${ }^{1}$ Assist. Prof. Dr., Nisantasi University, Faculty of Economics and Administrative Sciences, Department of \\ Business \\ ${ }^{2}$ Research Assistant, Istanbul Bilgi University, School of Health Sciences, Department of Health \\ Management \\ ${ }^{3}$ Assoc. Prof. Dr., Namık Kemal University, Faculty of Economics and Administrative Sciences, Department \\ of Political Science and Public Administration
}

\begin{abstract}
Keywords:

Public Service

Announcement, Health

Communication,

Social Marketing,

Content Analysis

Correspondence:

burcu.inci@nisantasi.edu tr

Public service announcements are informative short films that are made with the purpose of increasing the awareness of the society and/or creating behavioral changes. Also, they are communication tools used within the context of social marketing. One of the main themes of public service announcements which may have a substantial impact on masses is "health theme". Tobacco, blood donation, breast milk, obesity, and diabetes themed public service announcements which aimed to protect and improve health are examples of health communication as a part of social marketing. The purpose of the current study was to evaluate all the public service announcements in the Republic of Turkey, Ministry of Health's web site with a content analysis. Within this scope, characteristics of 52 healththemed public service announcements are analyzed according to nine main categories which include primary health issue, primary goal, target audience, role of the message source/ spokesperson, sex of the message source/ spokesperson, estimated age of the message source/ spokesperson, message appeal, message frame, and type of the PSA. Because of the increased importance of social marketing, it is estimated that the findings of this study will be beneficial for both public and private sectors besides non-governmental organizations.
\end{abstract}

CAIMI Journals 
Public service announcement (PSA) is a noncommercial advertisement that tries to modify public attitudes and behavior by raising awareness about specific issues such as blood donation, obesity, and suicide and it communicates information by using traditional and new media tools to publicize an issue of relevance or interest to the public (Klimes Dougan \& Lee, 2010). In recent years, PSAs have been started to being broadcasted on Internet as an alternative advertising media. For example, in order to reach young audience, the U.S. government's National Youth Anti-Drug Media Campaign's 100 million USD budget contained significant funding for Internet advertising (Walther, DeAndrea, Kim, \& Anthony, 2010). If produced correctly and broadcasted on the appropriate media tools, PSAs are very important in creating awareness, educating, informing, and motivating various target groups for critical social issues (Toncar, Reid, \& Anderson, 2007). The purpose of the current study is to evaluate all the public service announcements in the Republic of Turkey, Ministry of Health's web site with a content analysis.

\section{The Literature Review}

There are a great number of persuasion research about attitude change and corresponding behavior change; however, PSAs are designed without taking advantage of this information in general. Since this current producing procedure is based mostly on creative inspiration, the majority of the PSAs have gained only limited success. Therefore, Atkin and Freimuth (as cited in Bator \& Cialdini, 2000) offered a step-by-step guide for PSA campaign designs including preproduction stage and pretesting stage.

In preproduction stage, prior to the PSA campaign design, in order to discover as much as possible about the target audience, their attitudes and behaviors should be researched. According to the results of these research, campaign objectives can be specified, strategies can be drafted, and the message can be matched to the audience.

Pretesting stage requires the procedure of gathering reactions from the intended audience based on first types of messages before they are completed. Also, during and after a PSA campaign, the design implementation and efficacy should be assessed.

Celebrity-endorsed PSA campaigns try to capitalize upon the reputation of celebrities who can draw the attention of large public audiences (Shead, Walsh, Taylor, Derevensky, \& Gupta, 2011). Social learning theory proposes that people are more likely to model another's behaviors when they believe they are similar to the model in question. Thus, when a person perceives a similarity with the celebrity, he or she is more likely to be affected by the celebrity's behaviors. However, it does not mean that using celebrity spokespersons instead of non-celebrity spokespersons in the PSA is always better. Credibility, personality, and public image of the spokesperson, and spokesperson-issue match will affect the PSA success all together (Shead et al., 2011).

Although the previous literature largely addresses health-themed PSAs related to smoking cessation, violence reduction, and HIV prevention (Martiniuk, Secco, Yake, \& Speechley, 2010), unfortunately health problems are not limited to these issues. Hence, there is an important need for academic research about the PSAs related to other health problems. By the help of these research, effectiveness of the PSAs can be increased. 
PSA campaigns progressively invite the members of the general public to develop their own PSAs and share them on user-generated content (UGC) websites such as YouTube due to the problems that are likely to arise when PSAs do not involve collaboration between practitioners and their target audiences. In such cases, target audiences may perceive PSAs as strategies of social control. Therefore, PSA campaigners should consider using UGC websites as alternative channels. Enabling target audiences to participate in the activity of generating and spreading PSAs will make the campaigns more reliable (Paek, Hove, Jeong, \& Kim, 2011). When YouTube.com is browsed and searched for "Public Service Announcement about health", it will be seen that there are approximately 103.000 results, millions of page views, and thousands of comments as of this writing moment. Some of these videos are usergenerated and some of them are generated by non-governmental organizations and governments.

PSAs which use television spots, internet videos, posters, and brochures are one of the most typical elements of the social marketing campaigns. The goal of PSAs range from awareness to behavior change; however, social marketing often touches on resistant behaviors that may be difficult to change by PSAs alone. There are two types of PSAs as "help-self" and "help-other". The aim is improving oneself in some manner in "help-self" PSAs such as stopping the usage of drugs whereas the aim is encouraging the public to donate time or money in "help-other" PSAs. The appeal for most of the "help-self" PSAs is fear (Reichert, Heckler, \& Jackson, 2001). In 2005, efforts of the United Nations Children's Fund Belgium (UNICEF Belgium) was an example of "help-other" PSA which illustrates the horrors of war by using Smurfs with the goal of raising 150,000 USD to assist former child soldiers in Burundi, Congo, and Sudan. This PSA campaign was so prosperous that traffic on the UNICEF website and its link to the PSA expanded. Also, this campaign succeeded in stimulating word of mouth which means public and media talked about it. As a result, UNICEF Belgium raised over 750,000 Euros and it can easily be said that this PSA reached its goal (Hatfield, Hinck, \& Birkholt, 2007).

Should a persuasive PSA message clearly draw conclusions or should the receivers made encouraged to draw their own conclusions? According to the literature, PSA messages that have an explicit conclusion or recommendation are more effective than the others (Wilson, 2007).

Health communication is the kind of study and use of methods to influence and inform individual and also community decisions that improve health. Communication methods are used to increase and create public awareness of a disease, change individual behavior to prevent or control a disease, its causes, and treatment, educate public about a disease, change a person's or group's attitudes about a disease, advocate for policy changes in favor of disease control and prevention, and create social norms that favor healthful living. Functional health communication programs recognize and create order in audience segments, reach audiences through known channels, and deliver precise and scientifically based messages from reliable sources (Freimuth, Linnan, \& Potter, 2000).

According to Bull, Holt, Kreuter, Clark, and Scharff's (2001) study, if individuals like, attend to, and understand the health information presented in PSAs, a change in the behavior related to health will be facilitated. In order to make people like the message and perceive it as relevant, PSAs should present information in ways that are attractive, informative, 
encouraging, new, and useful. Telling people the "right" way to behave is not sufficient; the message should also provide practical suggestions in compliance with the target audience's lifestyle (Grow \& Christopher, 2008).

Health communication campaigns have developed comprehensive health behaviors, including seat belt use, dietary change, medication use, exercise, dental care, family planning, use of health services, and screening for diseases. In these campaigns, a lot of different communication tools such as posters, handouts, PSAs, discussion groups, workplace or clinicbased counseling, and in-school presentations are being used (Snyder, 2007). When developing health interventions, health communicators face with a number of decisions which include the primary goal of the intervention, its target audience, and the appeal of messages for the intervention (Fishbein \& Cappella, 2006).

Much attention has been given to the uses of the mass media to change attitudes and behavior, and also to persuade audiences to protect their health. However, research indicates that newspapers, magazines, radio, and television are not very persuasive channels for behavior change. Especially after 2000s, public health experts started seeking to take advantage of the Internet's capacity to serve as a new media channel for health information. By the help of this new media, health statistics and disease information are widely available to health professionals and the public (Cassell, Jackson, \& Cheuvront, 1998).

According to the literature, the average health campaign affects the target audience by about 5 percentage points. Success rates of nutrition campaigns for fruit and vegetable consumption, fat intake, and breastfeeding have been slightly higher than other health issues. A study which discusses the factors affecting success rates of these campaigns concluded that campaigns that consider the specific behavioral goals of the intervention, target populations, communication activities and channels, message content and presentation, and techniques for feedback and evaluation should have the ability to make changes in health behaviors (Snyder, 2007).

Effective health messages in the PSAs have to engender desired changes in target audiences' perceptions of their personal health risks and show the benefits of recommended actions. In order to encourage attitude and behavior change, typically informational and fear appeals are being used in health-themed PSAs (Keys, Morant, \& Stroman, 2009). PSAs often use fear appeals because they can change behavior by motivating attitude and intention change. A fear appeal is a persuasive communication attempting to revive fear, promoting protective motivation and self-protective action. A fear appeal attempts to revive fear by presenting a threat (e.g., "serious painful injury") to which the audience is sensitive (e.g., "car accident") and is severe (e.g., "people die from car accidents"). This kind of PSAs recommend a specific action (e.g., "by not texting and driving, you are less likely to have an accident") at the end. Such a communication effort will stimulate the audience for "safety conditions" hopefully (Lennon \& Rentfro, 2010). Most of the health communication campaigns use fear appeal in their messages. However, these kinds of messages may backfire if target audiences do not believe they are able to effectively expel a health problem. Consequently, fear appeals should be used with caution. According to the results of Witte and Allen's meta-analysis (2000) health communicators should always ensure that a high-threat 
fear appeal is accompanied by an equally high-efficacy (or greater) message; because lowefficacy messages produce defensive responses in people (Witte \& Allen, 2000).

There is not a general agreement on the effectiveness of fear appeal campaigns. Although some level of anxiety revival may be a desirable motivator, generating high level of anxiety can cause some people to ignore the campaign messages. This ignorance is called "defensive avoidance" which is minimized, when the anxiety- receiving message carries specific information about actions that people can take to protect themselves. The degree of defensive avoidance depends on the interactions between the message content and characteristics of the audience (Elderi et al., 2004).

In health communication messages can be presented in either a positive or a negative frame (this is also known as gain versus loss frame). A positive message frame highlights the agreeable behavioral results of obeying the message advocacy (e.g., a teenager stops smoking and attains approving looks), whereas a negative message frame gives special importance to the unfavorable behavioral results of noncompliance (e.g., a teenager starts smoking and forgoes approving looks) (Zhao \& Pechmann, 2007).

According to the regulatory focus theory, there are two types of consumers with different motivational orientations, namely promotion-focused consumers and prevention-focused consumers. It is estimated that approximately half of consumers are naturally promotion focused, while the other half are prevention focused (Zhao \& Pechmann, 2007). Health communicators consider this theory as well as commercial marketers and they design their messages for both promotion-focused and prevention-focused target audiences. A persuasive message can be designed in eager messages by focusing on achieving success or in vigilant messages by focusing on preventing failure. A regulatory fit can enhance the effectiveness of the persuasive message. In reference to regulatory fit, promotion-focused target audiences tend to be more susceptive to the presence or absence of positive messages, whereas prevention-focused target audiences tend to be more susceptive to the presence and absence of negative messages (Kees, Burton, \& Tangari, 2010).

"Health education" and "health promotion" are two main fields on which health communication research focuses. The goal of health education is encouraging individuals to adopt healthy living behaviors. So the media messages created for health education deals with providing health information and health education research is largely concerned with the accuracy of the health information presented and its effect on the target audience. In other respects, health promoters are more 'media friendly', they utilize from famous spokespeople and the principles of social marketing. Research on health promotion is mainly concerned with how well the message reaches or speaks to a specific target audience or can be evoked by them (Finlay \& Faulkner, 2005). Mass media campaigns promote healthy behaviors and discourage unhealthy behaviors. When mass media campaigns combine with other kinds of interventions, generally the positive impacts increase. However, when used perfectly media alone can have remarkable positive impacts on health-related attitudes, beliefs, and behaviors (Zimmerman, Palmgreen, Noar, Lustria, Lu, \& Horosewski, 2007).

There are three theories which have been widely used in health behavior research and interventions. They can be summarized as follows (Fishbein \& Yzer, 2003): 
Health Belief Model: This model suggests that in order for an individual to perform a recommended protective behavior, the individual must believe that he or she is at risk for acquiring a serious negative health outcome and the advantages of carrying out the suggested behavior outweigh the costs of performing that behavior.

Social Cognitive Theory: According to this theory, there are two factors that determine the probability that an individual will adopt a health-protective behavior or not. First, an individual must assume that the advantages of performing the behavior outweigh the costs. Second, the person must have a sense of self-efficacy which is about the belief that she or he can perform the recommended behavior.

Theory of Reasoned Action: This theory recommends that the representation of an established behavior is basically determined by the strength of a person's aim to execute that behavior. Two determinants of the intention are the person's attitude (person's overall positive or negative feeling) toward performing the behavior and/ or the person's subjective norm concerning the behavior (the person's perception about the opinions of the closest people to his or her on he or she should or should not perform the behavior). Attitudes are a function of behavioral beliefs and their evaluative aspects; subjective norms are viewed as a function of normative beliefs and motivations to comply.

\section{Social Marketing}

Social marketing utilizes from commercial marketing in order to change individual and social behaviors and it has four focal points as health, preservation, grassroots movement, and environment (Kaçar, Kartal, \& Kahraman, 2014). Social marketing concept was first used in 1971 in order to define the usage of marketing process and tenets for social issues. Indeed, social marketing creates demand for "social products" such as woman's rights, health research, blood donation, and stopping the usage of drugs by the help of traditional marketing concepts as segmentation, targeting, positioning, and marketing communication (Reichert, Heckler, \& Jackson, 2001).

Although social marketing uses the principles of commercial marketing, instead of selling products and services, the aim of social marketing is to design and implement programs to promote socially beneficial behavior change. Such as in commercial marketing, social marketing process includes understanding the target audience by the help of marketing research; because unless a marketer is able to understand audience attitudes and beliefs, he/she will not be able to affect behavior in response to a message. Also, social marketers examine their competitors and utilize effective techniques as commercial marketers do. Moreover, social marketers are being engaged in some branding activities by developing branded health behaviors as being a nonsmoker, being physically active, or using a condom in an effort to encourage those behaviors (Evans, 2008). One of the most successful social marketing campaigns is "The Heart Truth" which was launched by the National Heart, Lung, and Blood Institute in 2002 and it was the first federally-sponsored national campaign. Its aim was increasing awareness among women about their risk of heart disease. Within this social marketing campaign, an extensive research was used to plan, implement, and evaluate the 
campaign in which "Red Dress" has been used as a national symbol. This symbol has become a powerful appeal to large masses of women and has given acceleration to the campaign's strategy about partnership development, media relations, and community action (Long, Taubenheim, Wayman, Temple, \& Ruoff, 2008).

Social marketing uses the marketing mix variables - product, price, promotion, and place - and reinterprets these for a particular social issue (Finlay \& Faulkner, 2005). In social marketing, product is the desired behavior for the target audience. For example, in the VERB campaign (a social marketing campaign to increase physical activity among youth), the product was physical activity which is a voluntary action that requires personal choice and internal motivation. Price represents a balance of product benefits and costs to an individual. In the VERB campaign the costs can be financial (e.g., price of a sports center), psychological (e.g., feeling sick to participate in physical activity), environmental (e.g., the neighborhood does not have any sports center), or related to time (e.g., busy work schedule). Place is where the target audience either performs the behavior or accesses services. For the VERB campaign, a place may be a youth-serving organization, park or recreation department, school, public or private sports organization. Promotion covers all of the communication mix elements as advertisements, public relations, direct marketing, selling promotions, and personal selling that are multiple ways to reach the target audience to promote the benefits of the behavior change (Wong et al., 2004).

Social marketing has six-step process including initial planning, formative research, strategy development, program development and pretesting, implementation, and evaluation. As it is clear, this process is the same as in commercial marketing (Catesi, Shafer, Diehl, \& Deal, 2011). Sometimes the distinction between the commercial marketing and social marketing can be blurred as when a restaurant promotes the nutritional value of their products. In this case the restaurant tries to increase its market share while improving the public health. This two aims are not exclusive, yet social concern generally masks the commercial interests for businesses. However, there is no commercial interest in nongovernmental organizations and public institutions, so their social marketing is only for social benefits (Lefebvre \& Flora, 1988).

Laws use threat or punishment to achieve behavior change and they are very effective when people will not receive an immediate benefit from the behavior change or will have to pay a high price (financial or emotional) for adopting the behavior change. Nevertheless, governments cannot control every social issue by laws. For example, governments cannot force mothers by laws to breastfeed although it is very healthy for the babies. In such cases social marketing can be the solution, because it manages behavior change by creating incentives or consequences that invite voluntary exchange (Quinn, Hauser, Bell-Ellison, Rodriguez, \& Frias, 2006). There is supporting evidence from the literature about the success of social marketing campaigns. Vallone, Duke, Cullen, McCausland, and Allen (2011) took advantage of longitudinal data to investigate the relationship between confirmed awareness of a national, branded, mass media smoking cessation campaign called EX and cessation results. They surveyed 4067 adult smokers at baseline and they made a follow-up study six months later. They measured campaign effects on cognitions about quitting, quit attempts, and 30-day abstinence. Results revealed that respondents who displayed confirmed awareness of the EX campaign were notably more likely to expand their level of agreement on a cessation-related 
cognitions index from baseline to follow-up. People with confirmed campaign awareness had a $24 \%$ considerable opportunity in comparison with those who did not have enough knowledge of the campaign of making a quit effort.

It is very clear that there is much overlap in the "social marketing" and "health communication" approaches and PSAs are communication tools for these two. However, the main difference between them is that social marketing can be used to change behaviors somewhat outside of health. For example, a social marketing campaign on increasing physical activity may be used in promoting the active use of public transportation. Also generally social marketing campaigns include a long-term while most of the health communication campaigns include a short-term (Bauman, Madill, Craig, \& Salmon, 2004).

\section{Method}

Content analysis refers to a research technique for the objective, systematic, and quantitative description of the manifest content of communication. Objectivity requires that the analysis be based on explicitly formulated rules which allow two or more researchers to obtain the same results from the same data. A systematic analysis requires that the inclusion or exclusion of categories be done according to consistently applied rules in order to avoid biasing the results toward the researcher's hypothesized outcomes. Quantification refers to measurement of the emphasis or omission of any analytic category in order that results can be statistically summarized and interpreted (Zimmer \& Golden, 1988). Qualitative content analysis goes beyond solely counting words as opposed to quantitative content analysis. Present applications of qualitative content analysis display three different approaches including conventional, directed, or summative. In all of these approaches content of text is being interpreted in a subjective manner through the systematic classification process of coding (Hsieh \& Shannon, 2005). In this exploratory study, qualitative content analysis has been used and this study focuses on the content and contextual meaning of the observed PSAs.

In the present study a directed content analysis has been used, because we utilized from prior research to develop the codes. According to Hsieh and Shannon (2005) with a directed content analysis, the researcher uses existing theory or prior research findings to develop the initial coding scheme prior to beginning to analyze the data, and codes are defined before and during data analysis. Content analysis methodology was employed because it facilitates to describe the use of visual and linguistic elements in videos and also allows researchers to provide a representation of the facts and a guide to action as well as draw replicable and valid inferences from the data (Byrd-Bredbenner, 2002).

Creating categories is the core feature of qualitative content analysis. A category refers to a group of content that shares a commonality and categories must be comprehensive and commonly exclusive (Graneheim \& Lundman, 2004). To determine content analysis categories of this study, we used the other research in the literature (Fishbein \& Cappella, 2006; Freimuth et al., 2000; Kaçar et al., 2014; Reichert et al., 2001; Shead et al., 2011; Toncar et al., 2007; Zhao \& Pechmann, 2007). Eventually nine main categories are identified, namely primary health issue, primary goal, target audience, role of the message source/ spokesperson, sex of the message source/ spokesperson, estimated age of the message source/ spokesperson, message appeal, message frame, and type of the PSA. 
There are 52 health-themed PSAs in the Republic of Turkey, Ministry of Health's web site and all of them are assessed in this study. In other words, the research has been made on the population and we did not select a sample. There are health-themed PSAs prepared by different organizations besides Ministry of Health in Turkey. These kinds of PSAs are not within the scope of this study for the reason that they are not inside the Ministry of Health's web site. So, assessed PSAs are seemed to show the fields which are of great importance to Ministry of Health in public informing.

Two researchers (one of them is from public administration sciences and the other is from health sciences) used the instrument developed for this study to analyze the PSAs in the Republic of Turkey, Ministry of Health's website. This instrument was a structured form which included all of the nine categories and most of their subcategories were obtained from the literature, but some subcategories are defined during data analysis. Three researchers (all of the authors of this study) reviewed and discussed the instrument before the data collection process to establish uniformity. Different discipline backgrounds of the researchers enabled them to assess PSAs according to different viewpoints with a more objective approach.

Firstly, by using the instrument, two researchers viewed and coded the PSAs independently from each other. The procedure was to watch each PSA without recording any data, and then code the PSA using the study instrument. Then, after they completed their individual coding, they came together to compare if there were any differences in their codes. This comparison showed that the percentage of agreement was $92 \%$ which means high intercoder reliability. Intercoder reliability (agreement) is a critical component of the content analysis and without it measures are worthless. Although intercoder reliability does not ensure validity, when it is not present, the data cannot be considered valid (Lombard, Snyder-Duch, \& Bracken, 2002). In the few PSAs where coding differed, two researchers discussed the differences to reach an agreement. This process has been completed between 25.07.201606.08.2016.

\section{Results}

Qualitative content analysis that is used in qualitative descriptive studies, is a powerful and effective form of analysis of verbal and visual data which is directed toward summarizing the informational contents of that data. "Quasi-statistical analysis style" may be used by summarizing the data numerically with descriptive statistics. But the end result of counting is not a quasi-statistical rendering of the data, because there is an effort to understand not only the manifest, but also the latent content of data (Sandelowski, 2000). In this study quasistatistical analysis style is used and all of the descriptive findings are shown in the Figures below.

As it can be seen from Figure 1, primary health issues in the assessed PSAs are as follows, respectively; tobacco and tobacco products $(36 \%)$, obesity $(15 \%)$, hand washing $(6 \%)$, family physician (6\%), hospital appointment phone line (6\%), organ donation $(6 \%)$, vaccination (5\%), breast milk (4\%), blood donation (4\%), ambulance and emergency services (4\%), flu prevention $(2 \%)$, residential care $(2 \%)$, compassion $(2 \%)$, and drinking milk $(2 \%)$. These percentages show that the highest PSA weighting belongs to usage of tobacco and tobacco products. It is an expected finding due to the World Health Organization (WHO) statistics related to tobacco and tobacco products. According to WHO, over 1.1 billion people smoked 
tobacco in 2015. Even though it is declining worldwide and in many countries, the commonness of tobacco smoking seems to be growing in the WHO Eastern Mediterranean Region and the African Region. In Turkey, prevalence of smoking any tobacco product among people aged 15 or older was $39.5 \%$ among males and $12.4 \%$ among females in 2015 . While these numbers follow a declining trend, Turkey still has many smokers. The second highest PSA weighting belongs to struggle with obesity in our population. Obesity is very prevalent in Turkey.

Figure 1 and Figure 2 show frequencies and percentages of the primary health issues in PSAs and frequencies and percentages of the primary goals in PSAs, respectively.

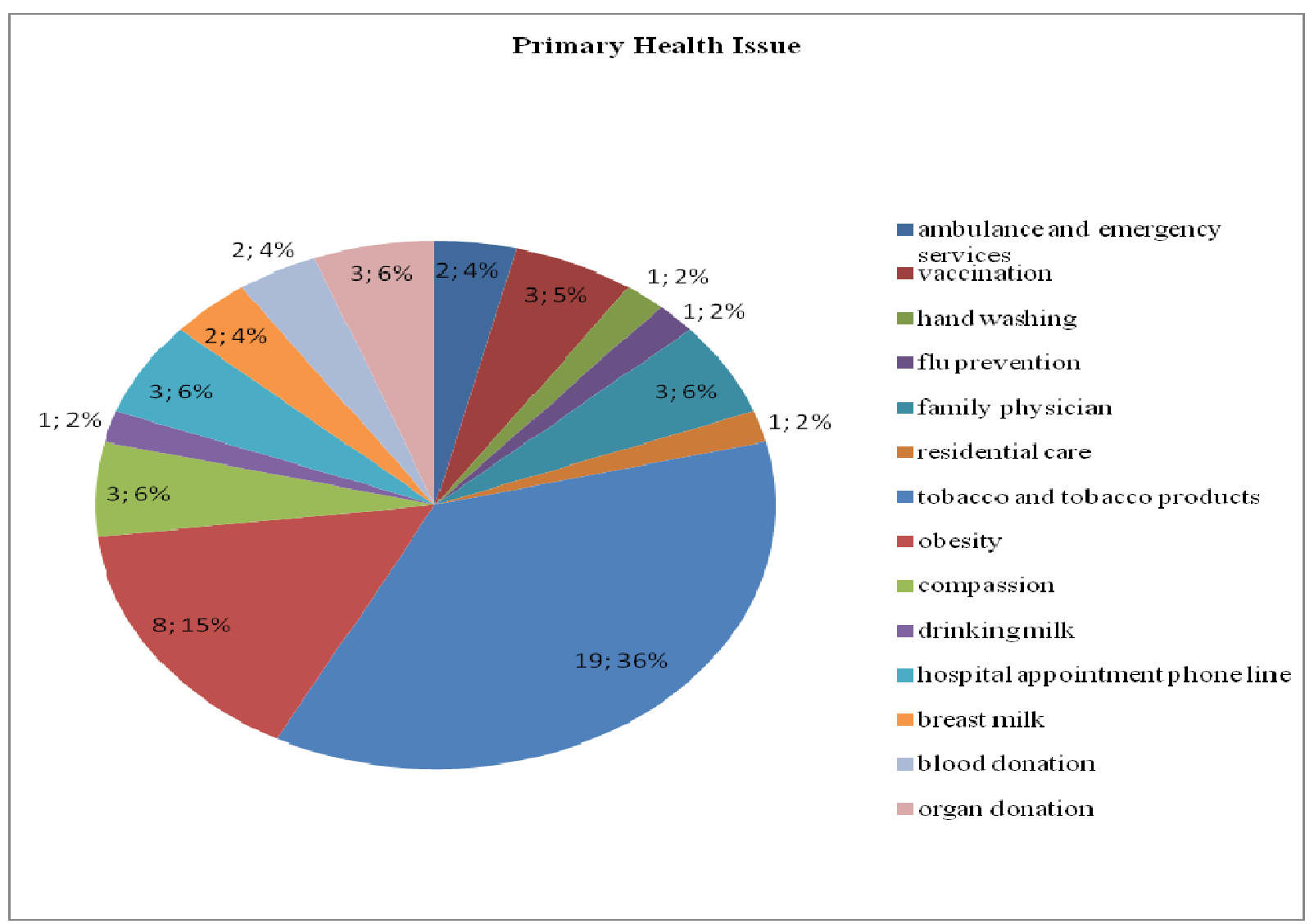

Figure 1. Frequencies and percentages of the primary health issues in PSAs 


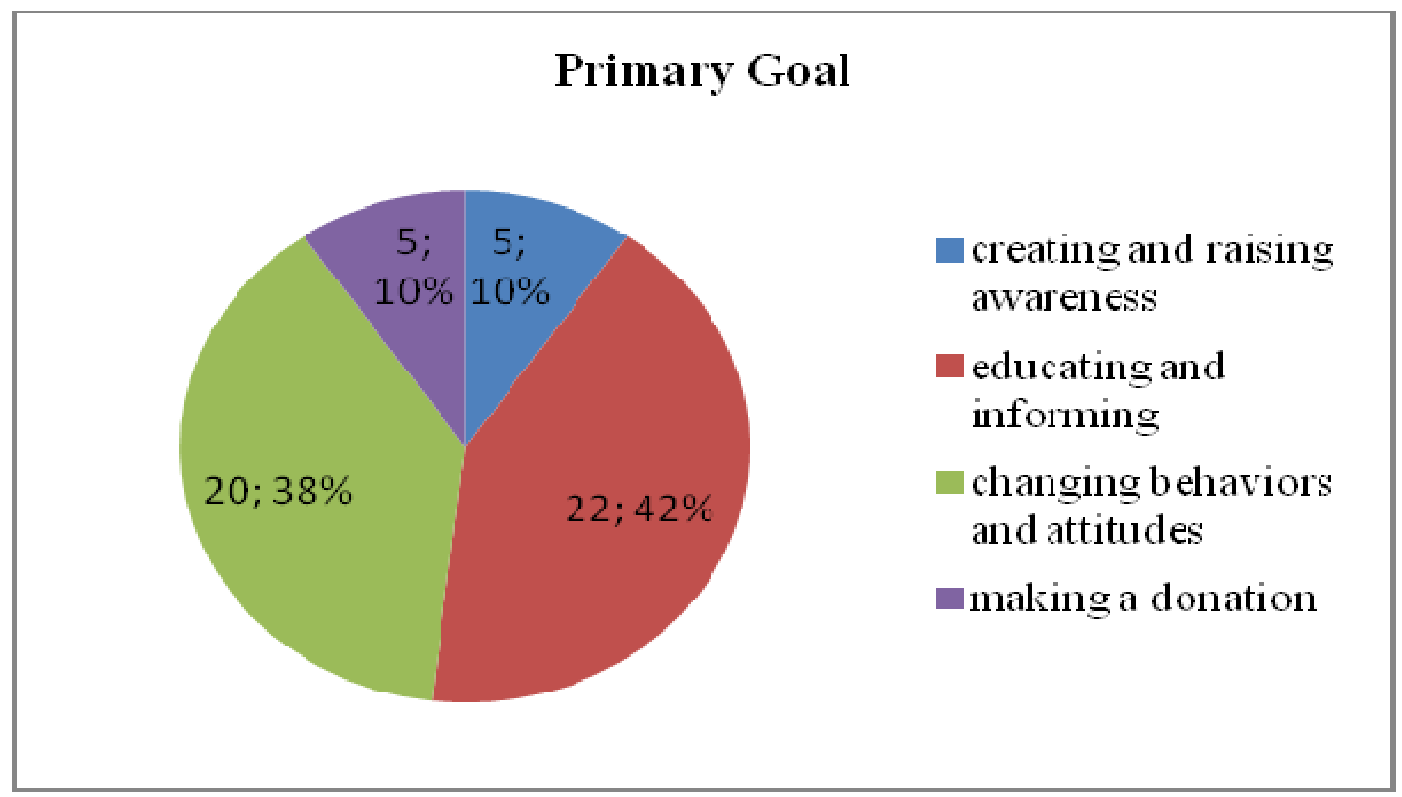

Figure 2. Frequencies and percentages of the primary goals in PSAs

The most common primary goal in the assessed PSAs is educating and informing (42\%). Changing behaviors and attitudes rank number two (38\%) while creating and raising awareness (10\%) and making a donation (10\%) follow it. These findings show that healththemed PSAs are especially for creating and increasing awareness in the society. Regarding educating and informing PSAs, hubble-bubble which is inside the tobacco and tobacco products have a local characteristic in this study. Hubble-bubble is being accepted as a traditional tobacco product in Turkish and Arabian cultures.

Figure 3 presents the frequencies and percentages of the target audiences in PSAs.

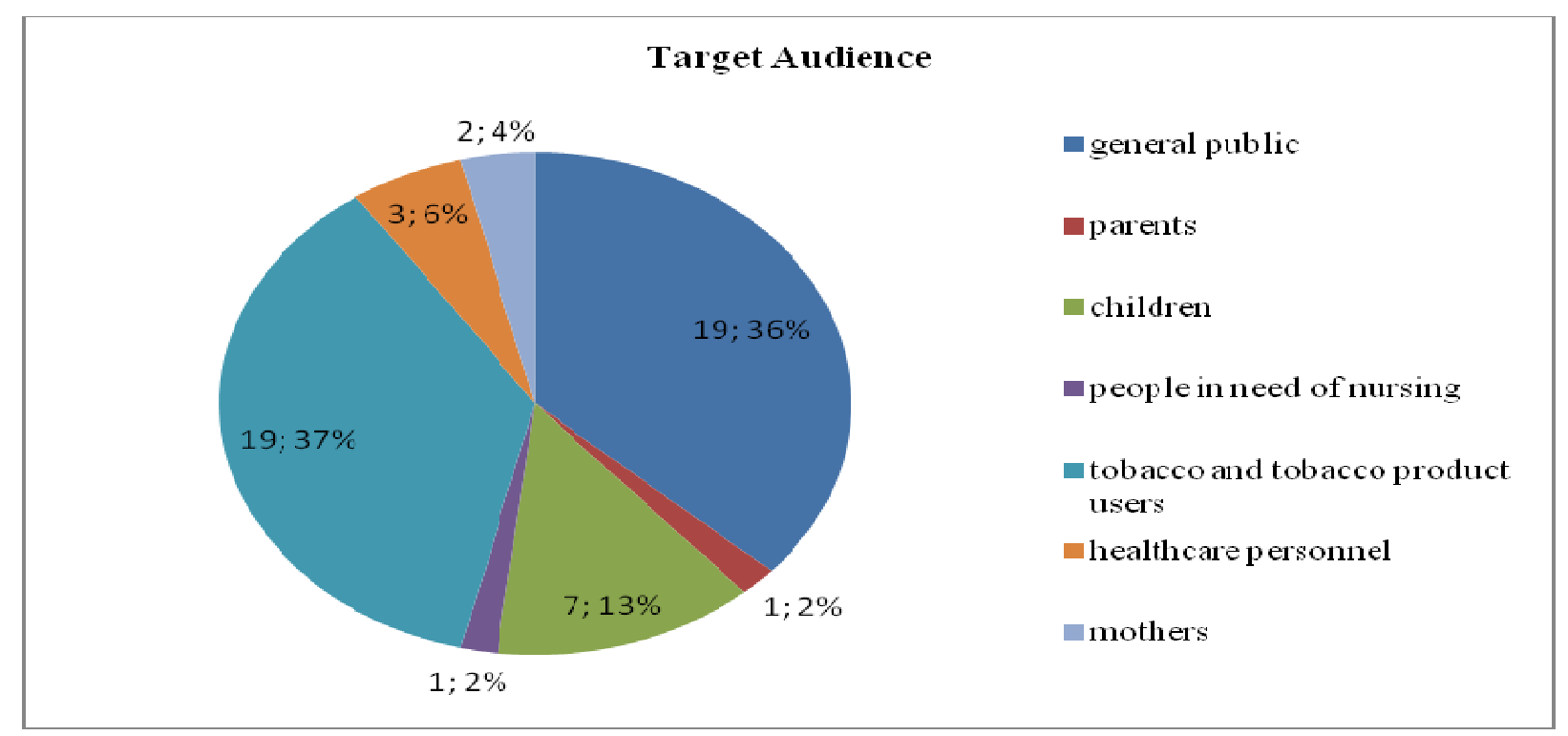

Figure 3. Frequencies and percentages of the target audiences in PSAs

The most common target audiences in the assessed PSAs are tobacco and tobacco product users $(36 \%)$ and general public (36\%). Children (13\%), healthcare personnel $(6 \%)$, mothers (4\%), people in need of nursing $(2 \%)$, and parents $(2 \%)$ follow them, respectively. So we 
think that some important target audiences such as pregnant women, cancer patients, alcoholics, and drugs users are neglected.

Figure 4 depicts the frequencies and percentages of the role of the message source/ spokesperson in PSAs.

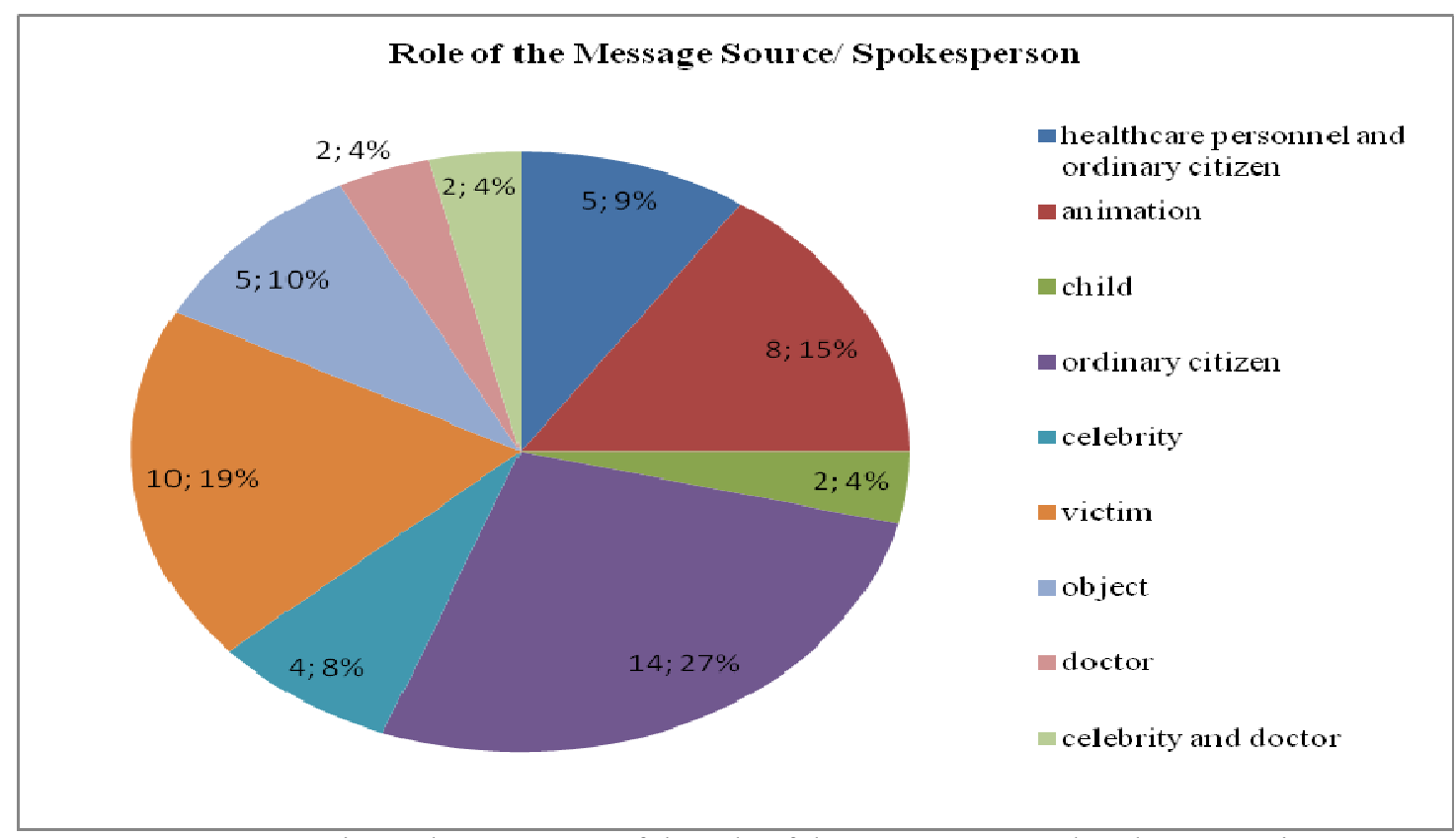

Figure 4. Frequencies and percentages of the role of the message source/ spokesperson in PSAs

As it can be seen from Figure 4, roles of the message source/ spokesperson in the assessed PSAs are ordinary citizen $(27 \%)$, victim $(19 \%)$, animation $(15 \%)$, object $(10 \%)$, healthcare personnel and ordinary citizen $(9 \%)$, celebrity $(8 \%)$, child $(4 \%)$, doctor $(4 \%)$, celebrity, and doctor $(4 \%)$, respectively. We think that ordinary citizen and victim roles create identification and they are more credible; thus, they are used frequently. The third highest PSA weighting belongs to animation role due to its high efficiency on child target audience.

Figure 5 illustrates the frequencies and percentages of the sex of the message source/ spokesperson in PSAs.

Sex of the Message Source/Spokesperson

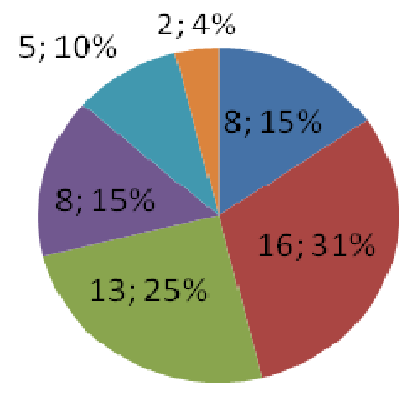

$$
\begin{aligned}
& \text { woman } \\
& \square \text { man } \\
& \text { woman and man } \\
& \text { animation } \\
& \text { object } \\
& \text { child }
\end{aligned}
$$

Figure 5. Frequencies and percentages of the sex of the message source/ spokesperson in PSAs 
When we look at the sex of the message source/spokesperson in the assessed PSAs, man $(31 \%)$ is in the first rank. Woman and man (25\%), woman (15\%), animation (15\%), object (10\%), and child (4\%) follow it respectively. High incidence of man usage in messages can be explained by patriarchal structure of Turkish society. Turkey is a male dominated country and usually men are accepted as an authority figure. Also, in Turkey, prevalence of smoking any tobacco product among people aged 15 or older was $39.5 \%$ among males and $12.4 \%$ among females in 2015. This can be another reason for the high usage of men. We included "object" as a separate category for the message source/ spokesperson here, because there is no person or animation character in some of the PSAs (such as showing only a hobble-bubble).

Figure 6 displays the frequencies and percentages of the estimated age of the message source/ spokesperson in PSAs.

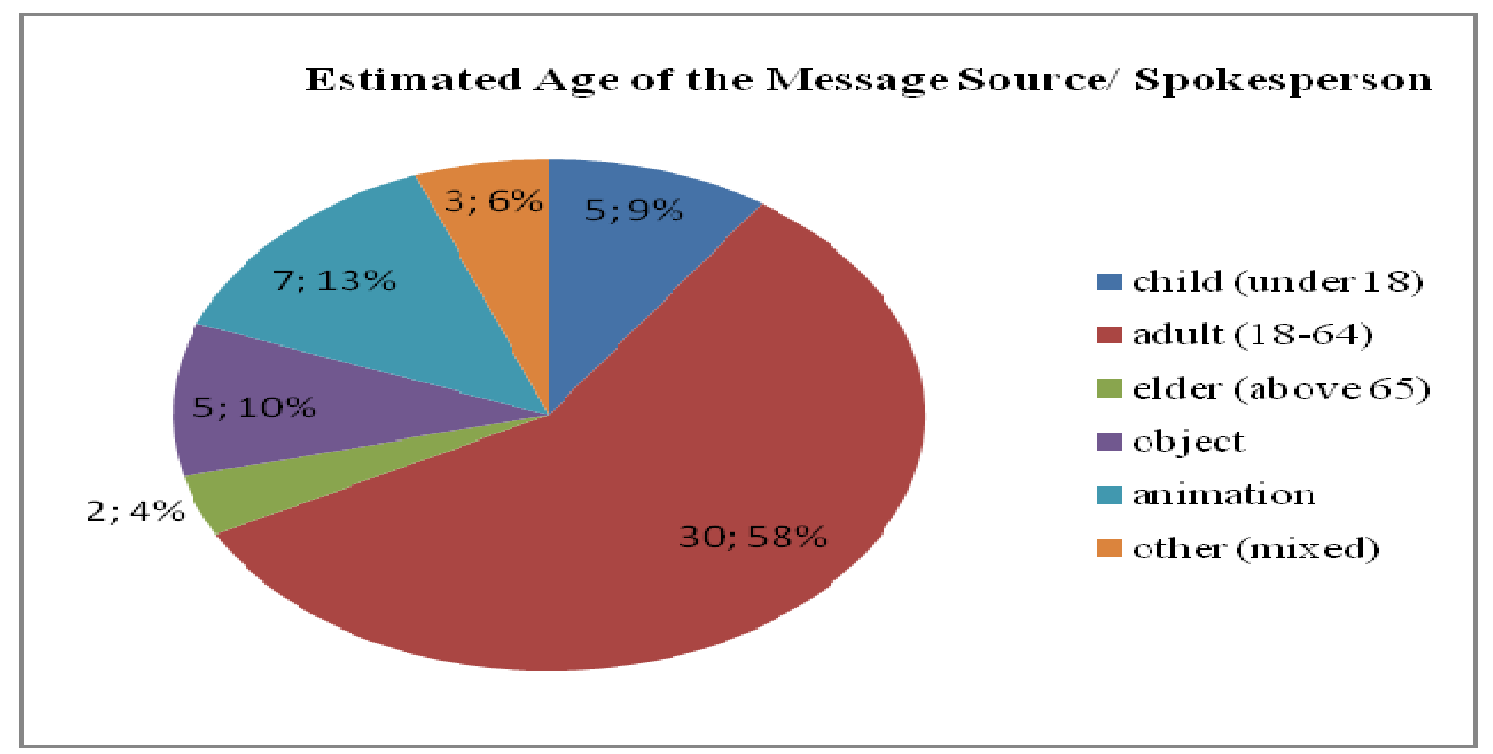

Figure 6. Frequencies and percentages of the estimated age of the message source/ spokesperson in PSAs

As it is seen in Figure 6, the most common age group of the message source/ spokesperson in the assessed PSAs is adults (58\%); animation (13\%), object $(10 \%)$, child $(9 \%)$, other $(6 \%)$ and elder (4\%) ages follow it respectively. If different age groups exist in the same PSA, we called them as other (mixed). Highest percentage for the estimated age of the message source/ spokesperson in PSAs belongs to adults (58\%). However, all of these adults are between 3164 ages interestingly. In other words, young adults who are between 18-30 ages do not exist in the assessed PSAs.

In PSAs related to the harms of tobacco and tobacco products, usually the experiences and regrets of adults (31-64) are the main message. Health problems do not begin in the early years of tobacco consumption, so nonexistence of young adults (18-30) in these PSAs is somewhat normal. It should be kept in mind that speed of organs' self-perpetuation decreases when people get older and irremediable damages may exist for people who used tobacco and tobacco products in some period of their lives. So the usage of young adults in tobaccothemed PSAs is very important for creating identification with them. Otherwise, it will not be easy for young adult smokers to feel identification with older smokers. Also malnutrition, drugs usage and lack of physical activity are among the main reasons of health problems 
among young adults. Unfortunately, in the assessed web site, we could not find any PSAs dealing with these issues depending on young adult message sources.

Figure 7 depicts the frequencies and percentages of the message appeal in PSAs.

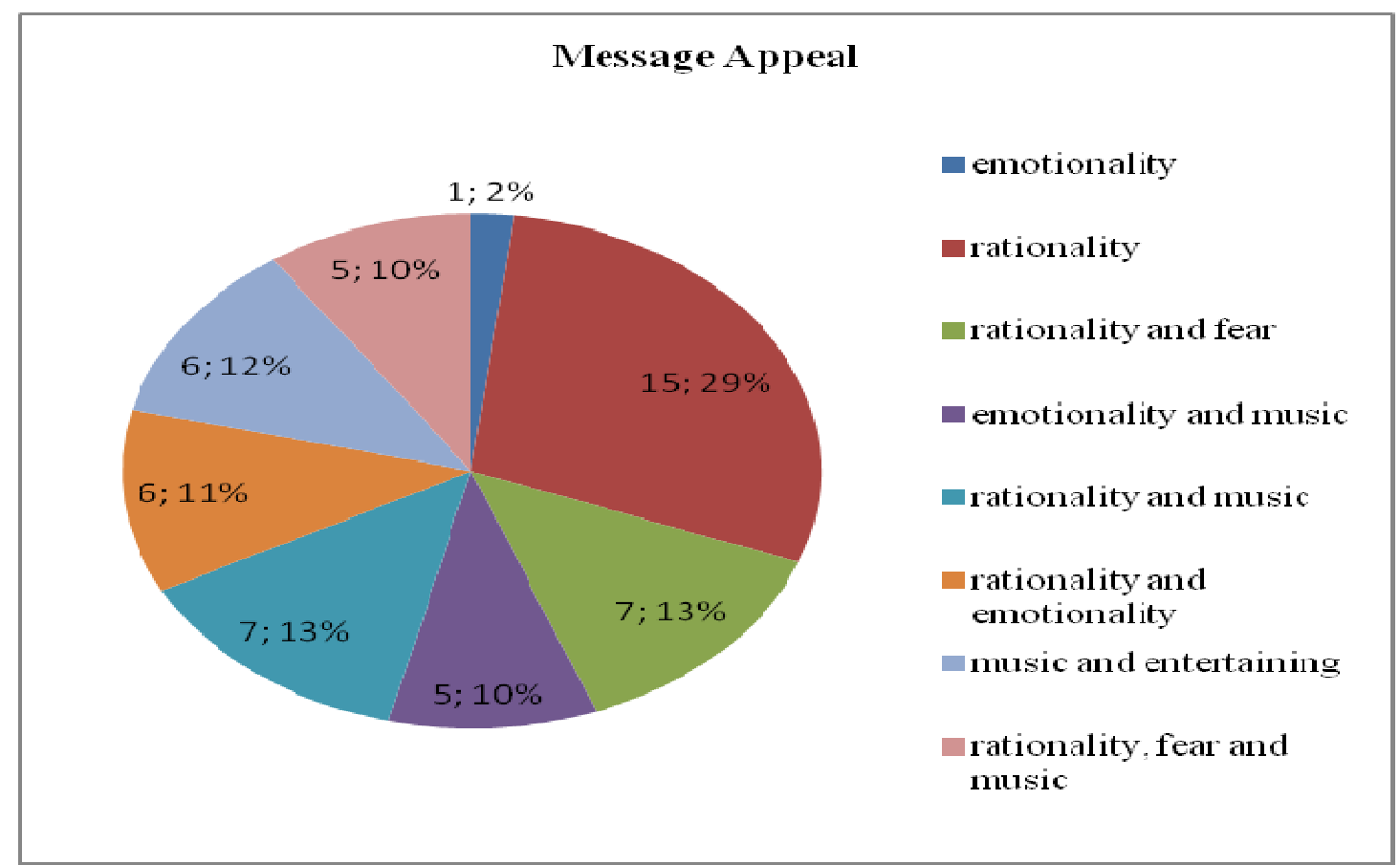

Figure 7. Frequencies and percentages of the message appeal in PSAs

Figure 7 shows that rationality has the highest percentage (29\%) for the message appeal in the assessed PSAs. Rationality and fear and rationality \& music (13\%) share the second rank with the same percentages. Rationality and emotionality (12\%), music and entertaining $(12 \%)$, rationality, fear and music (10\%), and emotionality and music (10\%) follow them, respectively. Lowest percentage belongs to emotionality $(2 \%)$. This shows the high dominance of rationality appeal and it is a surprising finding due to quite emotional Turkish people. Fear, music, and emotionality are used as supportive appeals besides other appeals in general; because they increase the attention and interest and trigger the desired emotions. This is known as AIDA (Attention-Interest-Desire-Action) model in marketing and action means convincing people to behave in a suggested way here. 


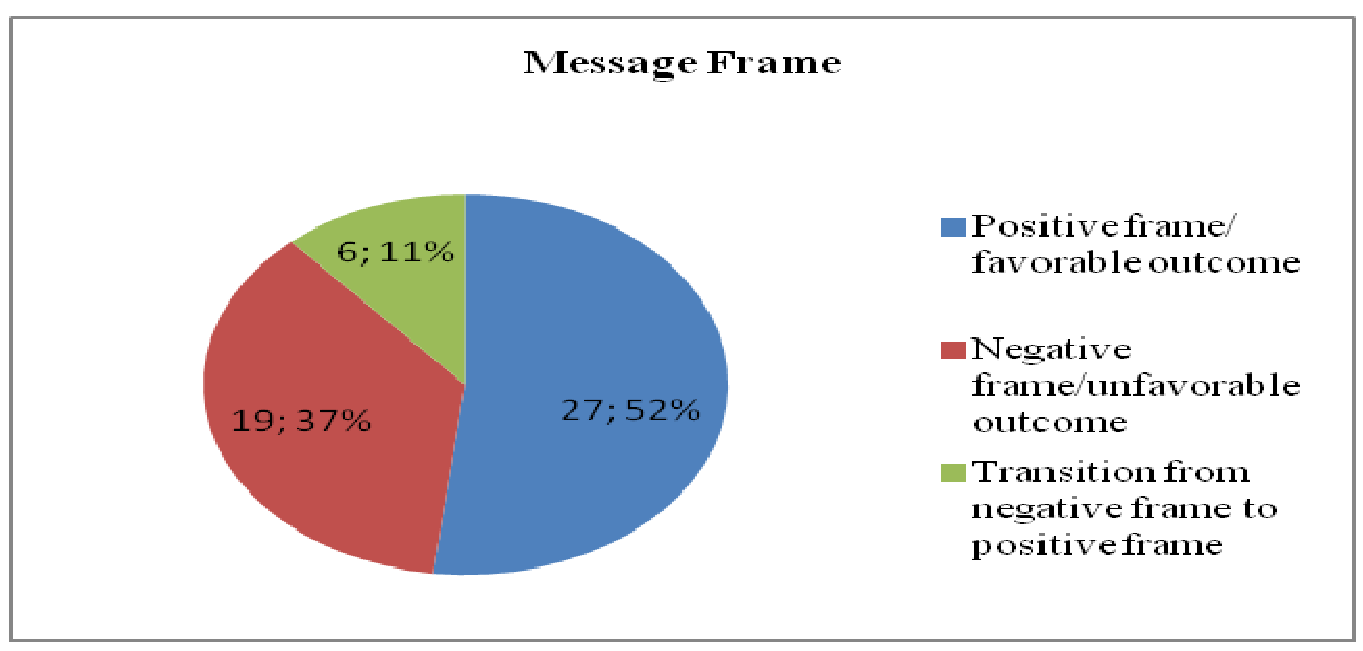

Figure 8. Frequencies and percentages of the message frame in PSAs

Table 8 which represents the frequencies and percentages of the message frame in PSAs indicates that the highest message frame in the assessed PSAs belongs to positive frame/favorable outcome (52\%) and negative frame/unfavorable outcome (37\%) follows it. In the literature, these two were the only categories of the message frame for PSAs. But after our content analysis, we discovered a third category which is transition from negative to positive frame $(11 \%)$. The reason for the high frequency of negative frame/unfavorable outcome message frame is tobacco and tobacco products themed PSAs.

Table 9 displays the frequencies and percentages of the type of the PSAs.

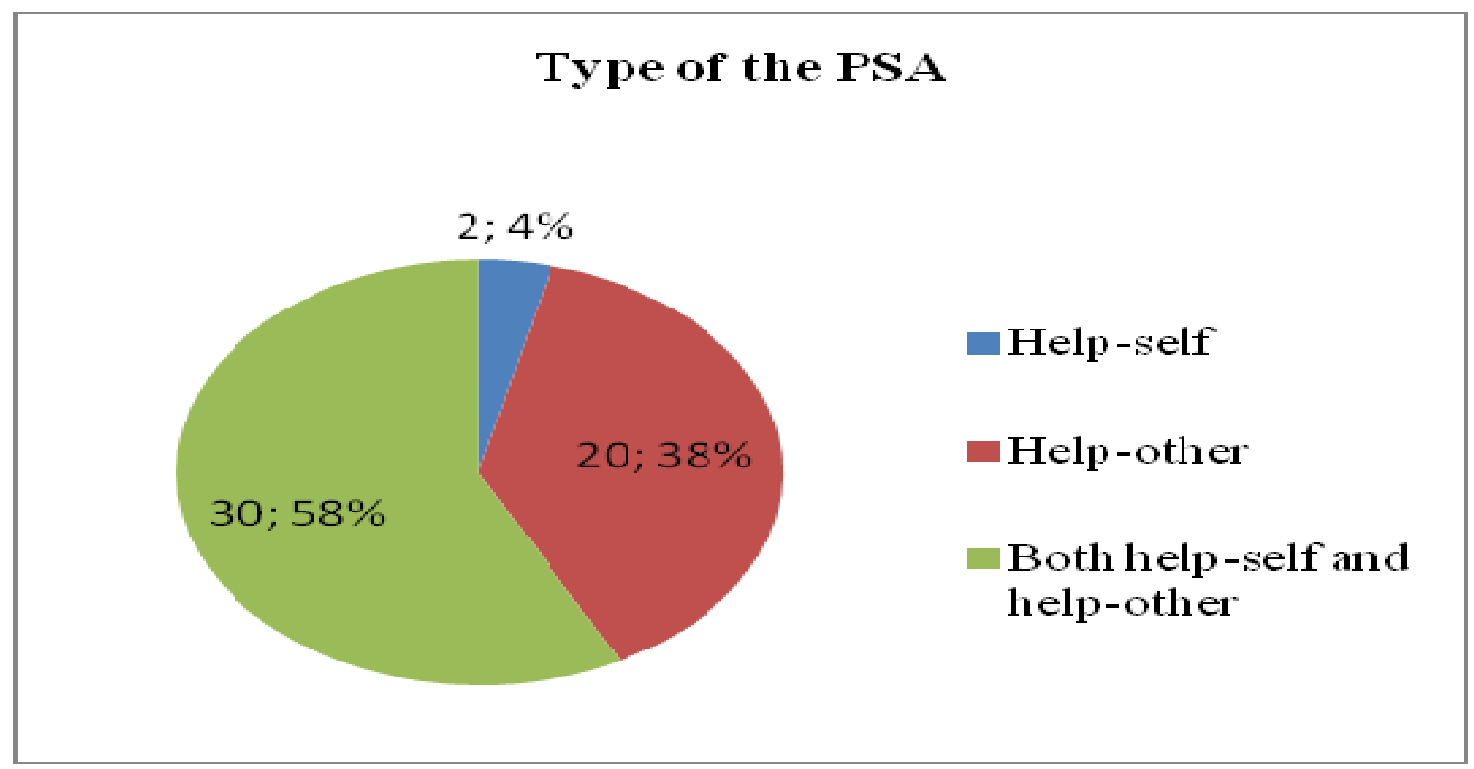

Figure 9. Frequencies and percentages of the type of the PSAs

At the end, the types of the PSAs are analyzed. There is a dominance of both help-self and help-other PSAs (58\%) in our population. Help-other (38\%) PSAs follow it, while help-self PSAs have a very little percentage (4\%). In fact, there is an interdependent relationship here. An unhealthy person possibly will not be able to help others and unhealthy life style of an individual usually affects those around him/her badly. For instance, if parents do not eat healthy foods, their children will not either. In such a case perhaps parents will not be affected 
by messages only "help-self" type, but when the bad effect on their children is underlined (help-other type), the effectiveness of the message can increase. The goal of help-other type PSAs is developing a conscious, susceptible, and healthy society and strengthening the health communication between the public.

\section{Discussion and Conclusion}

According to the findings of our content analysis, rationality message appeal and positive message frame are dominant in the assessed PSAs. Also, ordinary citizen and victim are the most used message source roles while males and adults are the dominant demographic characteristics of the message sources. Most of the assessed PSAs are educating, informing, and changing behaviors and attitudes based and usually help-other structured. The most frequent health issue is tobacco and tobacco products usage.

Tobacco and tobacco products usage is a global problem. About one third of the global adult male population smoke and 5 million smokers lose their lives due to tobacco use each year. Regarding the importance of this problem, Turkey takes tobacco control seriously and has made good progress in controlling the tobacco epidemic in collaboration with public health society and nongovernmental organizations. During recent years, Turkey has adopted laws restricting or banning smoking in all public places (Global Adult Tobacco Survey Turkey Report, 2010). Besides, the number of tobacco-themed PSAs increased and this shows how important this issue is to the Republic of Turkey, Ministry of Health. In some of these PSAs, big harms to children and other people exposed to passive smoke are shown and these messages increase the public support to restricting or banning smoking laws. However, there is a serious issue regarding hubble-bubble usage. General public usually does not know the danger of getting communicable diseases although hubble-bubble holder is being changed for each person. Educating and informing PSAs on hubble-bubble fill this information gap in Turkish society.

The only health issue in which fear appeal is used was tobacco and tobacco products in the assessed PSAs. Because the awareness about harms of the tobacco and tobacco products is high in the society, therefore, a more staggering theme probably will be more affective in creating a behavior change. Besides, although it is known that "passive smoking" is as dangerous as "active smoking", in the assessed PSAs active smoking messages were highly dominant and passive smoking messages were very limited. Therefore, passive smokers who are exposed to the harms of tobacco and tobacco products as much as active smokers should be more included in PSAs. In a study in 2012, it has been found that in the Ministry of Health's campaign, tobacco and tobacco products have unsuccessful dimensions due to using only elder people with too much fear appeal using cigarette-cancer identity with excluding other factors and giving direct messages. It was also underlined that the campaign was successful in dimensions such as using real life stories, slogan of the campaign, voice tone of the spokesperson, visuals related to respiratory insufficiency, and portraying of hospital environment. However, if the success parameter was "quitting the cigarette or thinking about to quit", the campaign has not been found successful. There was no reference to young people although smoking behavior is very common among them and potential smokers were excluded (Becerikli, 2012). 
There are no young adults (18-30 ages) in the assessed PSAs and this is a salient finding. This age group is especially important in giving messages about how tobacco and tobacco products may create health problems in early ages. Also, people usually start using tobacco and tobacco products before thirties; thus, usage of young adults in PSAs can prevent starting these products. At the same time, it is a clear fact that young people are more open to health problems arising from excessive use of alcohol, drugs usage, and sexually transmitted diseases. Absence of these issues in assessed PSAs can be explained by traditional social structures and values and the presence of more important issues that threaten public health and are not very common in Turkey. Although sometimes messages on these issues are being given through various programs and movies, it is still significant and should be evaluated within the scope of preventive and protective healthcare.

We noticed that healthy nutrition is merely linked to obesity in the assessed PSAs, but it should also be approached independently. Healthy nutrition is not an issue only about obese patients, all of the general public should be informed about it. Most of the chronic and nonchronic diseases can be prevented by healthy nutrition and this message should be given in PSAs.

According to 2013 data, cancer rate standardized to age is 267.9 per hundred thousand for men and 186.5 per hundred thousand for women in Turkey. In total, cancer incidence rate is 227.2 per hundred thousand. Nevertheless, there is not any PSA for creating awareness about the importance of early diagnosis related to cancer although early diagnosis is very critical in the treatment of this disease. Another important health issue is sexual health and again there is not any PSA related to this issue. PSAs on sexual health will be very informative for family planning, prophylaxis of venereal diseases, and prophylaxis of some cancer types. Therefore, we think that PSAs on early diagnosis of cancer and sexual health should not be ignored in Ministry of Health's web site. Another substantial deficiency is about drug abuse, there is no PSA on this issue although it creates vital danger especially for young adults. Ministry of Health may have worries for publishing PSAs on sexual health and drug abuse because of social norms or may think that these issues are not related to large masses. Non-governmental organizations and health institutions can fill this gap and they can produce PSAs on these ignored health issues.

Today technophilia (technology addiction) is a significant psychological problem among children and young people. Due to decreasing physical activity, technophilia can also be the underlying reason of some physical health problems. This kind of new and current issues may be located in PSAs.

Health phenomenon consists of social, physical, and psychological dimensions and these three have mutual interaction. However, in this study, we could not find any PSA related to psychological health in our population. If Ministry of Health produces some PSAs on this issue, it will be very beneficial for the public that most of the members need psychological consultancy. In these PSAs, awareness should be developed with underlying that people have the opportunity to get psychological consultancy services from some public hospitals and municipalities. Because although there are lots of people with psychological problems, some of them do not get any consultancy due to high charges of private consultancy services. Even worse, some of the psychological problems are transmissible to other people and in the long run, they can cause physical health problems. 
As a result, assessed PSAs show diversity to some extent, however this diversity should be increased in the suggested fields. Moreover, we can conclude that Ministry of Health produces PSAs with different contents and features each year follows the novelty, supports the creativeness, and sees PSAs as important health communication tools.

The most important limitations of this study arise from the qualitative content analysis methodology. First of all, the population was small, 52 PSAs are not adequate for making generalizations. There are many health-related PSAs and some of them are produced by nongovernmental organizations, but they are not within the scope of this study.

Content analysis is an entirely descriptive method which outlines what is there, but may not exhibit the underlying motives for the observed pattern. In other words, this study focuses just on what there is in the assessed PSAs but not underlying motives for these PSAs. Another limitation is about the availability of material; because of the dynamic nature of the Internet, population in our study can change at any moment. This study is limited to PSAs in the Republic of Turkey, Ministry of Health's official web site which is analyzed between 25.07.2016 - 06.08.2016.

Although we tried to maximize the intercoder reliability, content analysis is subject to an error related to intercoder reliability. This situation can be seen as a limitation. Also this methodology is inherently reductive; it is always possible for coders to miss important details especially when they are following a structured form as in our study.

Because of the increased importance of social marketing and health communication, it is estimated that the findings of this study will be beneficial for public and private sectors besides non-governmental organizations. So under this title, we will list some of our suggestions.

Intensity of tobacco and tobacco products usage among young adults is high in Turkey, but this group is ignored in PSAs. Therefore, this age group should be included in social marketing campaigns with effective PSA messages. The usage of more rational appeals or metaphors instead of fear appeals to increase the effectiveness of messages is also suggested. Another important issue is obesity and Ministry of Health increased its efforts on this field. Although tobacco and tobacco products usage and obesity are two main reasons of cancer, there are no PSAs related directly to cancer prevention or early diagnosis of cancer. Thus, we think there is a gap here; Ministry of Health should also produce PSAs dealing with this issue.

Although using celebrities in PSAs may be remarkable, they are not very believable and may be perceived as fictional. Consequently, high usage rate of ordinary citizens and victims in the assessed PSAs seem reasonable due to their more realistic nature. According to the results of a related study, a victim was the most credible and believable spokesperson in PSAs while a national celebrity was the least credible and believable message source. Interestingly, a local celebrity was more credible and believable than the national celebrity, but no more than a victim (Toncar et al., 2007).

PSAs create public awareness and behavior and attitude changes; correspondingly, they contribute to the economy of nations. Because they are tools for increasing preventive health services and by the help of PSAs, the costs of curative health services decreases. As a result, total health expenditures decreases and becomes more balanced. According to TurkStat (Turkish Statistical Institute) 2014 data, total health expenditures are summarized in Table 1. 
Health Expenditures Statistics by Service Providers, 2014 (million Turkish Liras)

\begin{tabular}{|c|c|c|c|c|c|c|c|c|}
\hline & \multirow[b]{2}{*}{ General Total } & \multicolumn{4}{|c|}{ General Government } & \multicolumn{3}{|c|}{ Private Sector } \\
\hline & & Total & $\begin{array}{c}\text { Central } \\
\text { Government }\end{array}$ & $\begin{array}{c}\text { Local } \\
\text { Government }\end{array}$ & $\begin{array}{c}\text { Social } \\
\text { Security }\end{array}$ & Total & Households & Other \\
\hline $\begin{array}{l}\text { Total Health } \\
\text { Expenditure }\end{array}$ & 94.75 & 73.38 & 21.28 & 0.74 & 51.35 & 21.36 & 16.81 & 4.54 \\
\hline
\end{tabular}

TurkStat data shows that the share of government health expenditures inside the total health expenditures is $77.45 \%$. Share of social security expenditures $(70 \%)$ is the highest in the government health expenditures. Highest share of expenditures belongs to curative health services in total health expenditures. Great importance of preventive health services becomes prominent by these statistics clearly; because owing to preventive health services both diseases are prevented before their existence, and thus life quality and length of individuals are improved by early diagnosis and heavy health costs of the government decreases. Accordingly, we think that there is a great need to PSAs related to preventive health awareness that especially underlines early diagnosis and encourages people to have check-ups regularly.

This study only deals with health-themed PSAs, although there are various other themedPSAs which can be researched. These PSAs are generated by non-governmental organizations and governments. Therefore, in order to research these PSAs, web sites of non-governmental organizations and other governmental organizations such as Ministry of Family and Social Policies, Ministry of Labor and Social Security will be appropriate. Besides, user-generated content (UGC) websites such as YouTube will be useful sources for PSA analysis or PSAs published in traditional media may be analyzed.

Empirical studies on the effects of PSAs can produce interesting results. Different demographic groups may show significant various reactions to PSAs and/or different PSA topics may be more effective with different message appeals or message sources. If researchers can disclose these kinds of significant relations, PSA producers may design more effective messages. Also by including the control groups to experiments, the effects of PSAs on attitude, intention, and behavior can be measured.

Fear appeal in PSAs may cause "defensive avoidance" and this concept can be a valuable research field. Health-themed PSAs are able to decrease total health expenditures of governments; this important issue can be analyzed in a research by comparing costs and benefits of PSAs financially.

Different countries have different priorities about their social issues, so cross-cultural studies on PSAs can produce important findings which can guide the other countries with similar problems. Other suggestions for future research include the usage of PSAs in integrated marketing communications, an analysis on producers of PSAs and their production processes, and usage of qualitative techniques such as focus groups and depth interviews for exploring the unknown about PSAs.

\section{References}

Bator, R. J., \& Cialdini, R. B. (2000). The application of persuasion theory to the development of effective proenvironmental public service announcements. Journal of Social Issues, 56(3), 527-541. 
Bauman, A., Madill, J., Craig, C. L., \& Salmon, A. (2004). Participation this mouse roared, but did it get the cheese? Canadian Journal of Public Health, 95(2), 14-19.

Becerikli, S. Y. (2012). Sağlık iletişimi çalışmalarında alımlama analizinin kullanımı: Odak grup çalışması yoluyla kamu kampanyaları ve reklam metinlerine ilişkin çapraz bir okuma pratiği. İstanbul Üniversitesi İletişim Fakültesi Dergisi, 43(2), 163-177.

Bull, F. C., Holt, C. L., Kreuter, M. W., Clark, E. M., \& Scharff, D. (2001). Understanding the effects of printed health education materials: Which features lead to which outcomes? Journal of Health Communication, 6(3), 265-279.

Byrd-Bredbenner, C. (2002). Saturday morning children's television advertising: A longitudinal content analysis. Family \& Consumer Sciences Research Journal, 30(3), 382-403.

Cassell, M. M., Jackson, C., \& Cheuvront, B. (1998). Health communication on the internet: An effective channel for health behavior change? Journal of Health Communication, 3, 71-79.

Catesi J. R., Shafer, A., Diehl, S. J., \& Deal, A. M. (2011). Evaluating a county-sponsored social marketing campaign to increase mothers' initiation of HPV vaccine for their pre-teen daughters in a primarily rural area. Social Marketing Quarterly, 17(1), 4-26.

Elderi R. W., Shults, R. A., Sleet, D. A., Nichols, J. L., Thompson, R. S., \& Rajab, W. (2004). Effectiveness of mass media campaigns for reducing drinking and driving and alcohol-involved crashes a systematic review. American Journal of Preventive Medicine, 27(1), 57-65.

Evans, W. D. (2008). Social marketing campaigns and children's media use. The Future of Children, 18(1), 181-203.

Finlay, S. J., \& Faulkner, G. (2005). Physical activity promotion through the mass media: Inception, production, transmission and consumption. Preventive Medicine, 40, 121-130.

Fishbein, M., \& Cappella, J. N. (2006). The role of theory in developing effective health communications. Journal of Communication, 56, 1-17.

Fishbein, M., \& Yzer, M. C. (2003). Using theory to design effective health behavior interventions. Communication Theory, 13(2), 164-183.

Freimuth, V., Linnan, H. W., \& Potter, P. (2000). Communicating the threat of emerging infections to the public. Emerging Infectious Diseases, 6(4), 337-347.

Graneheim, U. H., \& Lundman, B. (2004). Qualitative content analysis in nursing research: Concepts, procedures and measures to achieve trustworthiness. Nurse Education Today, 24(2), 105-112.

Grow, J., \& Christopher, S. (2008). Breaking the silence surrounding hepatitis C by promoting self-efficacy: Hepatitis C public service announcements. Qualitative Health Research, 18(10), 1401-1412.

Hatfield, K. L., Hinck, A., \& Birkholt, M. J. (2007). Seeing the visual in argumentation: A rhetorical analysis of Unicef Belgium's smurf public service announcement. Argumentation and Advocacy, 43, 144-151.

Hsieh, H. F., \& Shannon, S. E. (2005). Three approaches to qualitative content analysis. Qualitative Health Research, 15(9), $1277-1288$.

Klimes Dougan, B., \& Lee, C. Y. (2010). Suicide prevention public service announcements perceptions of young adults. Crisis, 31(5), 247-254.

Kaçar, A. İ., Kartal, B., \& Kahraman, A. (2014). Türkiye'deki çevreci sivil toplum kuruluşlarının sosyal pazarlama kampanyalarına ilişkin nitel bir araştırma. Temmuz, 14, 47-74.

Kees, J., Burton, S., \& Tangari, A. H. (2010). The impact of regulatory focus, temporal orientation, and fit on consumer responses to health-related advertising. Journal of Advertising, 39(1), 19-34.

Keys T. R., Morant, K. M., \& Stroman, C. A. (2009). Black youth's personal involvement in the HIV/AIDS issue: Does the public service announcement still work? Journal of Health Communication, 14(2), 189-202.

Lefebvre, R. C., \& Flora, J. A. (1988). Social marketing and public health intervention. Health Education Quarterly, 15(3), 299-315.

Lennon, R., \& Rentfro, R. (2010). Are young adults fear appeal effectiveness ratings explained by fear arousal, perceived threat and perceived efficacy? Innovative Marketing, 6(1), 58-65.

Lombard, M., Snyder-Duch, J., \& Bracken, C. C. (2002). Content analysis in mass communication: Assessment and reporting of intercoder reliability. Human Communication Research, 28(4), 587-604.

Long, T., Taubenheim, A., Wayman, J., Temple, S., \& Ruoff, B. (2008). “The heart truth:” Using the power of branding and social marketing to increase awareness of heart disease in women. Social Marketing Quarterly, 14(3), 3-29.

Martiniuk A. L. C., Secco, M., Yake, L., \& Speechley, K. N. (2010). Evaluating the effect of a television public service announcement about epilepsy. Health Education Research, 25(6), 1050-1060. 
Paek, H. J., Hove, T., Jeong, H. J., \& Kim, M. (2011). Peer or expert? The persuasive impact of YouTube public service announcement producers. International Journal of Advertising, 30(1), 161-188.

Quinn, G. P., Hauser, K., Bell-Ellison, B. A., Rodriguez, N. Y., \& Frias, J. L. (2006). Promoting pre-conceptional use of folic acid to Hispanic women: A social marketing approach. Maternal \& Child Health Journal, 10(5), 403-412.

Reichert, T., Heckler, S. E., \& Jackson, S. (2001). The effects of sexual social marketing appeals on cognitive processing and persuasion. Journal of Advertising, 30(1), 13-27.

Sandelowski, M. (2000). Focus on research methods whatever happened to qualitative description? Research in Nursing \& Health, 23(4), 334-340.

Shead, N. W., Walsh, K., Taylor, A., Derevensky, J. L., \& Gupta, R. (2011). Youth gambling prevention: Can public service announcements featuring celebrity spokespersons be effective? International Journal of Mental Health and Addiction, $9(2), 165-179$.

Snyder, L. B. (2007). Health communication campaigns and their impact on behavior. Journal of Nutrition Education and Behavior, 39(2), 32-40.

Toncar, M., Reid, J. S., \& Anderson, C. E. (2007). Effective spokespersons in a public service announcement: National celebrities, local celebrities and victims. Journal of Communication Management, 11(3), 258-275.

Vallone, D. M., Duke, J. C., Cullen, J., McCausland, K. L., \& Allen, J. A. (2011). Evaluation of EX: A national mass media smoking cessation campaign. American Journal of Public Health, 101(2), 302-309.

Walther, J. B., DeAndrea, D., Kim, J., \& Anthony, J. C. (2010). The influence of online comments on perceptions of antimarijuana public service announcements on YouTube. Human Communication Research, 36, 469-492.

Wilson, B. J. (2007). Designing media messages about health and nutrition: What strategies are most effective? Journal of Nutrition Education and Behavior, 39(2), 13-19.

Witte K., \& Allen, M. (2000). A meta-analysis of fear appeals: Implications for effective public health campaigns. Health Education \& Behavior, 27(5), 591-615.

Wong, F., Huhman, M., Heitzler, C., Asbury, L., Bretthauer-Mueller, R., McCarthy, S., \& Londe, P. (2004) VERB ${ }^{\mathrm{TM}}$ — A social marketing campaign to increase physical activity among youth. Preventing Chronic Disease, 1(3), 1-7.

Zhao, G., \& Pechmann, C. (2007). The impact of regulatory focus on adolescents' response to antismoking advertising campaigns. Journal of Marketing Research, 44(4), 671-687.

Zimmer, M. R., \& Golden, L. L. (1988). Impressions of retail stores: A content analysis of consumer images. Journal of Retailing, 64(3), 265-293.

Zimmerman, R. S., Palmgreen, P. M., Noar, S. M., Lustria, M. L. A., Lu, H. Y., \& Horosewski, M. L. (2007). Effects of a televised two-city safer sex mass media campaign targeting high-sensation-seeking and impulsive-decision-making young adults. Health Education \& Behavior, 34(5), 810-826. 